'DDS, Graduate Student, Department of Dental Materials and Prosthodontics, Ribeirao Preto School of Dentistry, University of São Paulo, Ribeirao Preto, SP, Brazil.

BAAS, Technician, Department of Dental Materials and

Prosthodontics, Ribeirao Preto School of Dentistry, University of São Paulo, Ribeirao Preto, SP, Brazil.

${ }^{3}$ DDS, Master Student, Department of Restorative Dentistry, Ribeirao Preto Scholl of Dentistry, University of Sao Paulo, Ribeirao Preto, SP, Brazil.

${ }^{4} \mathrm{PhD}$, Researcher, Department of Dental Materials and

Prosthodontics, Ribeirao Preto School of Dentistry, University of São Paulo, Ribeirao Preto, SP, Brazil.

${ }^{5}$ PhD Student, Department of Dental Materials and Prosthodontics, Ribeirao Preto School of Dentistry, University of São Paulo, Ribeirao Preto, SP, Brazil.

${ }^{6} \mathrm{CDT}$, Technician, Department of Dental Materials and Prosthodontics, Ribeirao Preto School of Dentistry, University of São Paulo, Ribeirao Preto, SP, Brazil.

${ }^{7} \mathrm{PhD}$, Associate Professor, Department of Dental Materials and Prosthodontics, Ribeirao Preto School of Dentistry, University of

São Paulo, Ribeirao Preto, SP, Brazil.

Corresponding author: Fernanda de Carvalho Panzeri Pires-de-Souza

University of São Paulo, Ribeirão Preto School of Dentistry, Department of Dental Materials and Prosthodontics. Av. Do Café, $\mathrm{s} / \mathrm{n}^{\circ}$. Bairro Monte Alegre. CEP 14040-904

Ribeirão Preto - SP. Brazil

Phone: +551633153973

E-mail: ferpanzeri@usp.br

Received: March 07, 2018

Accepted: May 11, 2018

\section{Influence of aging on bond strength of artificial teeth to denture base acrylic resins}

\author{
Etiene Faria Aguiar ${ }^{1}$, Rafaella Tonani ${ }^{2}$, Fabiana de \\ Goes Paiola ${ }^{3}$, Michelle Alexandra Chinelatti ${ }^{4}$, Carolina \\ Noronha Ferraz de Arruda ${ }^{5}$, Julio César Souza da \\ Matta $^{6}$, Fernanda de Carvalho Panzeri Pires-de-Souza ${ }^{7}$
}

Aim: The aim of this study was to evaluate the bond strength of artificial teeth to different types of denture base resins when submitted to thermomechanical cycling (TMC). Methods: Sixty artificial mandibular first molars (Trilux, Vipi) were randomly divided into 3 groups according to denture base acrylic resins (Vipi Wave, Vipi Cril, and Vipi Cril Plus, Vipi). The teeth were fixed onto self-polymerizing acrylic resin bars $\left(0.5 \mathrm{~cm}^{2}\right.$ cross-section $\times 2 \mathrm{~cm}$ height), and the set was included in a metal flask using dental stone/silicone. After the dental stone was set, the bar was removed, and the denture base resin was packed and processed according to the group studied (Vipi Wave: 180 W/20 minutes + $540 \mathrm{~W} / 5$ minutes; Vipi Cril and Vipi Cril Plus: Water bath at $74^{\circ} \mathrm{C}$ for 9h). After polymerization, the samples were divided into 2 groups $(n=10)$, according to the TMC treatment received (simulation of 5 years of mastication or not). The samples were submitted to tensile bond strength test ( $1 \mathrm{~mm} / \mathrm{min})$, and the data ( $\mathrm{MPa}$ ) were statistically analyzed (2-way ANOVA, Bonferroni, $a=0.05$ ). The fracture interfaces were evaluated using a stereomicroscope (50x). Results: The bond strength results showed no statistically significant difference $(p>0.05)$ between the resins studied. TMC was significant $(p<0.05)$, demonstrating lower values for the bond strength of artificial teeth to Vipi Cril Plus. The predominant fracture type was cohesive in resin. Conclusions: It was concluded that there is no difference in bond strength between artificial teeth and the resins used for denture base. However, TMC decreases the bond strength values of artificial teeth and crosslink thermo-polymerizable acrylic resin.

Keywords: Cyclic loading. Acrylic resins. Denture, complete. Bond Strength. 


\section{Introduction}

Complete dentures have a positive effect on the quality of life of patients, not only for provides esthetics, but also function, once edentulism harms masticatory efficiency, the concentration of nutrients required by the body and the maintenance of the individual's intermaxillary relationship ${ }^{1}$, regardless in conventional or implant supported prostheses.

The dental material most used for fabrication of denture bases and tooth over the last 60 years has been acrylic resin, due to its low cost and easy processing ${ }^{2,3}$. Unfortunately, dental prostheses are subject to failures and the debonding of artificial teeth accounts for approximately $22 \%$ to $30 \%$ of the repairs carried out ${ }^{4,5}$.

Previous studies reported that the main causes of prosthetic failures are: tooth position in the alveolar ridge, incorrect occlusion, incorrect processing, different methods of preparation, contamination of the surfaces between the artificial tooth and denture base, and excessive forces during mastication ${ }^{1,4,5}$.

Considering that artificial teeth are essential parts of dentures, the bond between the teeth and denture base resin must be adequate, because this factor increases the strength and durability of the dental prosthesis ${ }^{6}$, but the debonding of denture teeth may become a greater clinical problem and increases laboratory costs ${ }^{7}$. The use of acrylic artificial teeth is preferable than other materials as ceramic teeth, due to the possibility of a chemical bond to the denture base resin by polymethyl methacrylate (PMMA) that is copolymerized with the cross-linking substances ${ }^{8}$.

Methods that may be used to increase the artificial tooth bond to the denture base resin include performing mechanical retentions, wear on the denture base surface ${ }^{9}$, and chemical treatment with monomer ${ }^{10}$, solvent, PMMA or silanization ${ }^{6,7}$.

Studies $2,7,11$ conducted about the bond strength of artificial teeth and denture base regarding the effect of static compression or tensile loads ${ }^{12,13}$ and thermalcycling ${ }^{2}$. However, the dynamic forces of mastication, the influence of fatigue loads and thermomechanical on the bond strength of artificial teeth, have not been considered or limited ${ }^{14,15}$. Accelerated aging conditions can indicate a performance degradation of the materials and bonding interface involved ${ }^{16}$. So, thermomechanical cycling can be used to simulate the oral condition and to evaluate the durability of the bond between the materials ${ }^{17}$.

Therefore, the aim of this study was to evaluate the influence of thermomechanical cycling on the bond strength of artificial teeth to different types of denture base resins. The study hypothesis was that the type of denture base resin and the thermomechanical cycling would not influence the bond strength of the artificial teeth to resins.

\section{Material and Methods}

Sixty artificial mandibular first molars and 3 thermoactived acrylic resins for denture base were selected (Table 1). 
Table 1. Acrylic resins for denture base used in the study and their respective characteristics.

\begin{tabular}{|c|c|c|c|c|}
\hline Material & Manufacturer & Composition & $\begin{array}{l}\text { Processing } \\
\text { Method }\end{array}$ & $\begin{array}{c}\text { Polymerization Method } \\
\text { (recommended by } \\
\text { manufacturer) }\end{array}$ \\
\hline $\begin{array}{l}\text { Vipi Wave } \\
\text { Microwave } \\
\text { polymerized } \\
\text { resin }\end{array}$ & \multirow{3}{*}{$\begin{array}{l}\text { VIPI Ind. Com. } \\
\text { Exp. Imp. } \\
\text { De Produtos } \\
\text { Odontológicos } \\
\text { Ltda, } \\
\text { Pirassununga, } \\
\text { SP, Brazil }\end{array}$} & $\begin{array}{l}\text { Powder: Polymethylmethacrylate, } \\
\text { Benzoyl Peroxide, } \\
\text { Biocompatible Pigments; } \\
\text { Liquid: Methylmethacrylate, } \\
\text { EDMA, Inhibitor }\end{array}$ & \multirow{3}{*}{ Pressing } & $\begin{array}{c}\text { Microwave oven } \\
180 \mathrm{~W} \text { for } 20 \mathrm{~min} / 540 \\
\mathrm{~W} \text { for } 5 \mathrm{~min}\end{array}$ \\
\hline $\begin{array}{l}\text { Vipi Cril Plus } \\
\text { Heat- } \\
\text { polymerized } \\
\text { crosslinked resin }\end{array}$ & & $\begin{array}{c}\text { Powder: Polymethylmethacrylate, } \\
\text { Benzoyl Peroxide, } \\
\text { Biocompatible Pigments; } \\
\text { Liquid: Methylmethacrylate, } \\
\text { Inhibitor fluorescent, EDMA }\end{array}$ & & $\begin{array}{l}\text { Water bath } 74^{\circ} \mathrm{C} \\
\text { for } 9 \mathrm{~h}\end{array}$ \\
\hline $\begin{array}{l}\text { Vipi Cril } \\
\text { Heat- } \\
\text { polymerized } \\
\text { resin }\end{array}$ & & $\begin{array}{c}\text { Powder: Polymethyl methacrylate, } \\
\text { Benzoyl Peroxide, } \\
\text { Biocompatible pigments; } \\
\text { Liquid: Methylmethacrylate, } \\
\text { inhibitor, EDMA }\end{array}$ & & $\begin{array}{l}\text { Water bath } 74^{\circ} \mathrm{C} \\
\text { for } 9 \mathrm{~h}\end{array}$ \\
\hline
\end{tabular}

\section{Sample Preparation}

Rectangular bars (cross-section of $0.5 \mathrm{~cm}^{2} \times 2.0 \mathrm{~cm}$ height) were prepared with self-cured acrylic resin (Vipi Flash, Vipi Dental Products, Pirassununga, SP, Brazil), according to methodology adapted from Consani et al. ${ }^{18}$ (2012). Acrylic artificial teeth were fixed on the bars with soft wax (Wilson, Polidental Ind\&Com. Ltda, Cotia, SP, Brazil). The tooth-wax bar set was included in dental stone (Gesso Pedra Creme, Gesso-RIO, Rio Claro, SP, Brazil) proportioned and mixed according to the manufacturer's instructions and included in a metal flask (MAC - Artigos Odontologicos e Protese Ltda., Sao Paulo, SP, Brazil).

Before hardening, five rectangular wax bars $(1.5 \times 3.5 \times 0.5 \mathrm{~cm})$ were included on the dental stone. After the dental stone hardening, the wax bars were removed and the stone molds were filled with laboratory silicone putty (Zetalabor, Zhermack, Rovigo, Italy). The artificial teeth were partially included into the silicone layer (Figure 1A), and then covered with another layer of silicone (Figure 1B). After dental stone insulation with petroleum jelly, the flask was filled with dental stone.
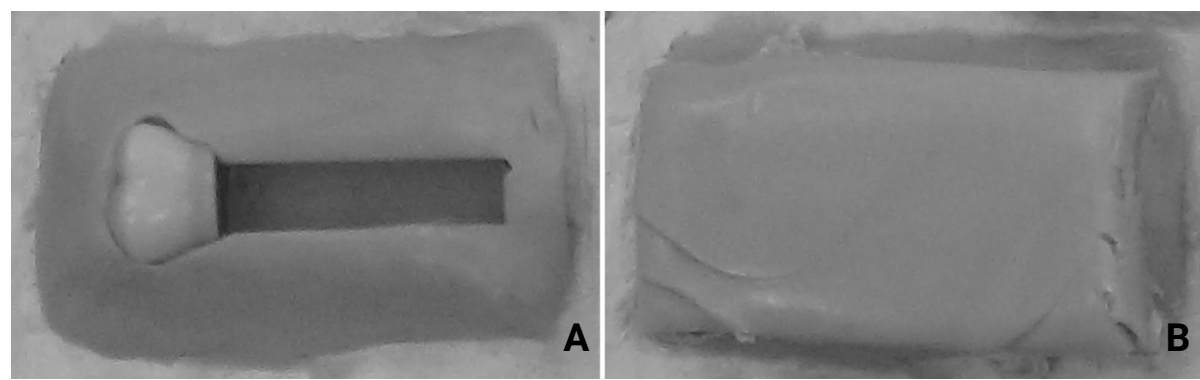

Figure 1. Initial preparation of samples. A) The artificial tooth was put into the silicone layer. B) Another layer of silicone covered the tooth. After stone set, the acrylic resin was included on the hole in silicon 
Once the dental stone had set, the flask was opened. The wax bars were removed and the wax residues on the ridge lap surface was removed with tap water. To improve the bond strength of the teeth to base resin, mechanical retentions were made in the surface of the ridge laps using a tungsten carbide bur (\# 6, KG Carbide; KG Sorensen, Cotia, SP, Brazil) at low speed of rotation (N270, Dabi Atlante, Ribeirao Preto, SP, Brazil). The operator used one bur for each ten teeth. After cleaning with compressed air, the mechanical retentions were etched with methyl methacrylate monomer ${ }^{19}$.

\section{Inclusion of Denture Base Acrylic Resins}

The teeth were randomly separated into three groups according to the denture resin used as the base. Specimens (Figure 2) were made with the tooth ridge lap surface attached to the acrylic resin, which was proportioned and manipulated according to the manufacturer's instructions. After inclusion, the flasks were submitted to 750 $\mathrm{kgf} \mathrm{load} \mathrm{hydraulic} \mathrm{pressure} \mathrm{to} \mathrm{remove} \mathrm{resin} \mathrm{excesses} \mathrm{and,} \mathrm{after,} \mathrm{to} 1000 \mathrm{kgf}$ load for approximately 20 minutes. The flasks were polymerized as described in Table 1.

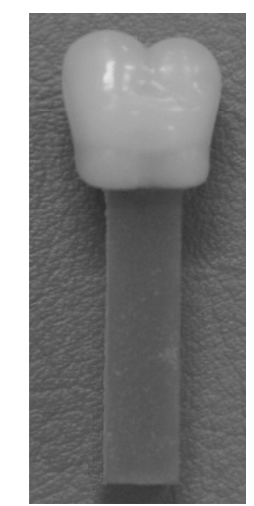

Figure 2. Sample prepared.

Twenty-four hours after polymerization, the specimens were deflasked after flask cooling at room temperature. Before testing, the resin bars were finished with abrasive stones, and the specimens stored in distilled water at $37^{\circ} \mathrm{C}$ for 7 days, to release the internal stress.

\section{Thermomechanical Cycling (TMC)}

The specimens of each group were divided into two subgroups $(n=10)$ according to the treatment performed; with or without thermomechanical cycling (TMC). Specimens that were not submitted to TMC (control group) were immediately tested after stored in water for 7 days.

Prior to the TMC, the specimens were fixed into rigid PVC rings $(16 \mathrm{~mm}$ height $\times 21$ $\mathrm{mm}$ in diameter) using putty silicone, and a parallelometer to verified if the specimens were perpendicular to the horizontal plane. The TMC (ER 37000; ERIOS, SP, 
Brazil) was performed at 1,200,000 cycles, with a load of $98 \mathrm{~N}(10 \mathrm{~kg})$, and frequency of $2 \mathrm{~Hz} / \mathrm{s}$. A rounded tip with $6-\mathrm{mm}$ in diameter was used as antagonist. The frequency used corresponds to 2 chewing movements per second ${ }^{20}$, which simulated 5 years of chewing ${ }^{21}$.

\section{Bond Strength Test}

After cycling, the specimens were fitted to a device with two adjustable clips: one adapted to the portion adjacent to the tooth, simulating a hook; and the other fixed to the end of the bar. The specimens were submitted to the bond strength test (Mechanical Test Machine, Emic - 1L-2000, Sao Jose dos Pinhais, PR, Brazil) with a tensile load speed of $1 \mathrm{~mm} / \mathrm{min}$. The bond strength values were recorded in MPa. The bonding area was $25 \mathrm{~mm}^{2}$ and the strength (MPa) was calculated by dividing the maximum force applied before fracture $(\mathrm{N})$ by the area $\left(\mathrm{mm}^{2}\right)$.

\section{Statistical Analysis}

The values of bond strength (MPa) were analyzed using 2-way ANOVA, and Bonferroni's test at a significance level of 5\% (Software GraphPad Prism 4.0 ${ }^{\circledR}$, GraphPad Software, Inc., La Jolla, CA, USA)

\section{Fracture Pattern Analysis}

The fracture patterns were analyzed with a stereomicroscope (Keyence Brazil, Sao Paulo, SP, Brazil) at 50x magnification, and classified as: A) adhesive - when there was debonding between resin and tooth; B) cohesive - in the tooth or in the resin; C) mixed - adhesive and cohesive fractures.

\section{Results}

\section{Bond Strength}

The mean values of bond strength (MPa) of the artificial teeth to the denture base resins are described in Table 2 . None of the specimens failed during TMC test.

Table 2. Comparison of bond strength mean values (MPa) ( \pm standard deviations) of artificial teeth to denture base resins as a function of the thermomechanical cycling (TMC)

\begin{tabular}{lccc}
\hline & \multicolumn{1}{c}{ Vipi Wave } & Vipi Cril Plus & Vipi Cril \\
\hline Control & $16.27( \pm 7.4)^{\text {aA }}$ & $21.52( \pm 8.8)^{\mathrm{aA}}$ & $17.60(6.2)^{\mathrm{aA}}$ \\
\hline With TMC & $12.13( \pm 5.6)^{\text {aA }}$ & $12.75( \pm 5.5)^{\mathrm{aB}}$ & $10.70(3.4)^{\mathrm{aA}}$ \\
\hline Different letters, lowercase in line and uppercase in column, & indicate statistically significant difference $(\mathrm{p}<0.05)$
\end{tabular}

When the resins were compared, there was no statistical difference $(p>0.05)$ in the bond strength. There was significant reduction $(p<0.05)$ in the bond strength values for the Vipi Cril Plus resin, and no effect $(p>0.05)$ on the other studied acrylic resins when submitted to TMC. There was no interaction between the factors $(p=0.5062)$. 


\section{Fracture Type Analysis}

Figure 3 presents the fracture mode for each group. The cohesive fracture in the resin was predominant in the specimens with and without TMC. The control group for microwaved resin presented the same occurrence for mixed fractures (50\%). The Vipi Cril Plus resin presented twice the mixed fracture on the group submitted to TMC (20\%) when compared with the group with no cycling (10\%).

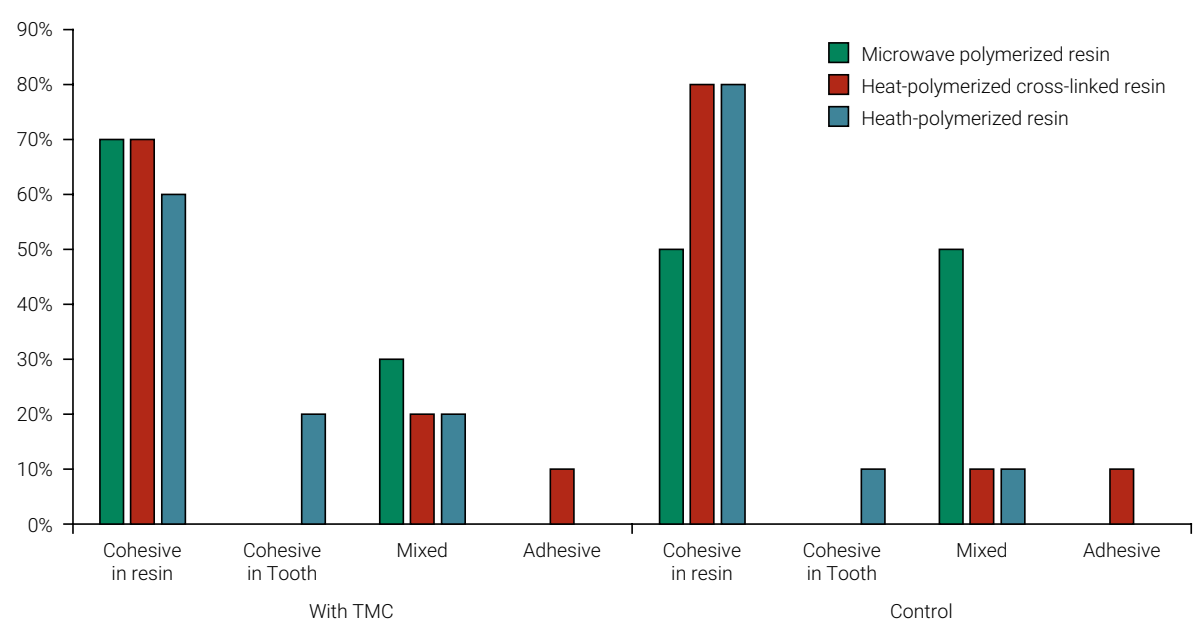

Figure 3. Distribution, in percentage, of the fracture types for each group. (TMC = Thermomechanical cycling)

\section{Discussion}

The aim of this study was to evaluate the tooth/resin bonding after TMC. The study hypothesis was that the type of denture base resin and the thermomechanical cycling would not influence the bond strength of the artificial teeth to resins. The results showed that there was no difference in the bond strength when the resins were compared. However, TMC reduced the bond strength of the artificial teeth to the Vipi Cril Plus resin, which allowed the hypotheses to be rejected.

The reduction in bond strength values for the Vipi Cril Plus resin after TMC may be explained by the degradation of the interface of the ridge lap/resin bond, as the mechanical stress associated with thermal changes can induce crack propagation through bonded interface ${ }^{22}$, explaining the lower bond strength found in this group.

However, the bond strength depends on the level of penetration of the monomer that plasticizes the surface and diffuses into the tooth acrylic resin ${ }^{13}$. The TMC cycles could change the ratio of monomer inter-penetration the denture tooth resulting in less strength of polymer networks formed 23,24 .

On the other hand, no influence of TMC was observed on the bond strength values between ridge laps and the other studied resins. This can be attributed to the lower levels of residual monomer verified in these resins ${ }^{25}$. Beside this, the water sorption 
and thermal expansion coefficient are different and inherent to each materia ${ }^{26}$. Based on this, the diffusion of water molecules at the interface between the artificial tooth and acrylic resin ${ }^{27}$ and different thermal expansion coefficients of the resins may result in differences in the bonding ability.

The TMC was used in this study because it can simulate intraoral conditions more closely. The heating-cooling process associated to simulated chewing can result in repeated expansion and contraction of the tooth and acrylic resin, stressing the bonding area, producing fatigue of the denture tooth/ridge laps interface, and decreasing the bond strength.

All groups and resins presented a higher prevalence of the cohesive fractures in the resin bars irrespective of submission to TMC test. This can be explained by the ridge laps mechanical retentions, which were able to improve the retentiveness.

The thermomechanical cycling is a suitable method for simulation of degradation of bond strength because the mechanical stress can induce crack propagation through bonded interfaces and the thermal changes can speed up this process ${ }^{28}$. However, there is no evidence that bonding failures in clinical practice occur as a result of thermomechanical stress and whether failures occur because of leakage in one or another layer in the bonded structure, which must be dependent on the glass transition temperatures of the bonded material ${ }^{28}$.

This study has several limitations. One is that it is not possible to know the exact difference in composition of the heat-polymerized and cross-linked heat-polymerized resin due to the lack of available manufacturer's information. Further study is needed of the chemical changes in the bonding surface between the resin and ridge laps surface. To overcome the limitations of in vitro tests, the bonding between denture teeth and acrylic resins should be evaluated using different methods.

It was concluded that there is no difference in bond strength between artificial teeth and the resins used for denture base. However, TMC decreases the bond strength values of artificial teeth and crosslink thermo-polymerizable acrylic resin.

List of abbreviations:

TMC - Thermomechanical cycling

PMMA - Polymethyl methacrylate

PVC - Polyvinyl chloride

\section{Conflict of Interest Disclosure}

All authors deny any financial and personal relationships with other people or organizations that could inappropriately influence the study.

\section{Acknowledgements}

This study was supported with scholarship by Sao Paulo State Research Foundation - FAPESP (grant number: 13/13529-0). 


\section{References}

1. Tôrres ACSP, Maciel AQ, de Farias DB, de Medeiros AKB, Vieira FPTV, Carreiro ADFP. Technical quality of complete dentures: influence on masticatory efficiency and quality of life. J Prosthodont. 2017 Nov 9. doi: 10.1111/jopr.12703.

2. Barbosa DB, Barão VAR, Monteiro DR, Compagnoni MA, Marra J. Bond strength of denture teeth to acrylic resin: Effect of thermocycling and polymerisation methods. Gerodontology. 2008 Dec;25(4):237-44. doi: 10.1111/j.1741-2358.2008.00218.x.

3. Cunningham JL. Shear bond strength of resin teeth to heat-cured and light-cured denture base resin. J Oral Rehabil. 2000 Apr;27(4):312-6.

4. Kurt M, Sarac YS, Ural C, Sarac D. Effect of pre-processing methods on bond strength between acrylic resin teeth and acrylic denture base resin. Gerodontology. 2012 Jun;29(2):e357-62. doi: 10.1111/j.1741-2358.2011.00480.x

5. Patil SB, Naveen BH, Patil NP. Bonding acrylic teeth to acrylic resin denture bases: a review. Gerodontology. 2006 Sep;23(3):131-9

6. Chung $\mathrm{K}-\mathrm{H}$, Chung $\mathrm{CY}$, Chung $\mathrm{CY}$, Chan DCN. Effect of pre-processing surface treatments of acrylic teeth on bonding to the denture base. J Oral Rehabil. 2008 Apr;35(4):268-75. doi: 10.1111/j.13652842.2007.01779.x

7. Meng GK, Chung KH, Fletcher-Stark ML, Zhang H. Effect of surface treatments and cyclic loading on the bond strength of acrylic resin denture teeth with autopolymerized repair acrylic resin. J Prosthet Dent. 2010 Apr;103(4):245-52. doi: 10.1016/S0022-3913(10)60038-8.

8. Yanikoglu DN, Duymus DZ, Bayindir DF. Comparative bond strengths of autopolymerising denture resin and light cured composite resin to denture teeth. Int Dent J. 2002 Feb;52(1):20-4.

9. Zuckerman GR. A reliable method for securing anterior denture teeth in denture bases. J Prosthet Dent. 2003 Jun;89(6):603-7

10. Saavedra G, Valandro LF, Leite FPP, Amaral R, Ozcan M, Bottino MA, et al. Bond strength of acrylic teeth to denture base resin after various surface conditioning methods before and after thermocycling. Int J Prosthodont. 2007 Mar-Apr;20(2):199-201.

11. de Chaves CAL, Regis RR, Machado AL, de Souza RF. Effect of ridge lap surface treatment and thermocycling on microtensile bond strength of acrylic teeth to denture base resins. Braz Dent J 2009;20(2):127-31.

12. Sanders JL, Levin B, Reitz P V. Comparison of the adaptation of acrylic resin cured by microwave energy and conventional water bath. Quintessence Int. 1991 Mar;22(3):181-6.

13. Takahashi Y, Chai J, Takahashi T, Habu T. Bond strength of denture teeth to denture base resins. Int J Prosthodont. 2000 Jan-Feb;13(1):59-65

14. Drummond JL, Bapna MS. Static and cyclic loading of fiber-reinforced dental resin. Dent Mater. 2003 May;19(3):226-31

15. Garoushi S, Lassila LVJ, Tezvergil A, Vallittu PK. Static and fatigue compression test for particulate filler composite resin with fiber-reinforced composite substructure. Dent Mater. 2007 Jan;23(1):17-23.

16. Kappert PF, Kelly JR. Cyclic fatigue testing of denture teeth for bulk fracture. Dent Mater. 2013 Oct;29(10):1012-9. doi: 10.1016/j.dental.2013.07.001.

17. Schneider RL, Curtis ER, Clancy JMS. Tensile bond strength of acrylic resin denture teeth to a microwave- or heat-processed denture base. J Prosthet Dent. 2002 Aug;88(2):145-50.

18. Consani RLX, Soave T, Mesquita MF, Sinhoreti MAC, Mendes WB, Guiraldo RD. Effect of repeated microwave disinfections on bonding of different commercial teeth to resin denture base. Gerodontology. 2012 Jun;29(2):e553-9. doi: 10.1111/j.1741-2358.2011.00516.x. 
19. Lagouvardos PE, Polyzois GL. Shear bond strength between composite resin and denture teeth: effect of tooth type and surface treatments. Int J Prosthodont. 2003 Sep-Oct;16(5):499-504.

20. Fontijn-Tekamp A, Slagter AP, Van Der Bilt A, Van'T Hof MA, Witter DL, Kalk W, et al. Biting and Chewing in Overdentures, Full Dentures, and Natural Dentitions. J Dent Res. 2000 Jul;79(7):1519-24.

21. DeLong R, Sakaguchi RL, Douglas WH, Pintado MR. The wear of dental amalgam in an artificial mouth: a clinical correlation. Dent Mater. 1985 Dec;1(6):238-42.

22. Chai J, Takahashi Y, Takahashi T, Habu T. Bonding durability of conventional resinous denture teeth and highly crosslinked denture teeth to a pour-type denture base resin. Int J Prosthodont. 2000 MarApr;13(2):112-6

23. Vallittu PK. Fibre-reinforced composites in root canal anchoring. Int Dent South Africa. 2006;8:20-7.

24. Barbosa DB, Monteiro DR, Barão VAR, Pero AC, Compagnoni MA. Effect of monomer treatment and polymerisation methods on the bond strength of resin teeth to denture base material. Gerodontology 2009 Sep;26(3):225-31. doi: 10.1111/j.1741-2358.2008.00262.x.

25. Yunus N, Harrison A, Huggett R. Effect of microwave irradiation on the flexural strength and residual monomer levels of an acrylic resin repair material. J Oral Rehabil. 1994 Nov;21(6):641-8.

26. Amin WM. Durability of acrylic tooth bond to polymeric denture base resins. Eur J Prosthodont Restor Dent. 2002 Jun;10(2):57-61.

27. Marra J, De Souza RF, Barbosa DB, Pero AC, Compagnoni MA. Evaluation of the bond strength of denture base resins to acrylic resin teeth: effect of thermocycling. J Prosthodont. 2009 Jul;18(5):438-43. doi: 10.1111/j.1532-849X.2009.00478.x.

28. Gale MS, Darvell BW. Thermal cycling procedures for laboratory testing of dental restorations. J Dent. 1999 Feb;27(2):89-99 